\title{
COMMON FIXED POINTS UNDER LIPSCHITZ TYPE CONDITION
}

\author{
Vyomesh Pant \\ Department of Mathematics Kumaon University, D.S.B. Campus \\ Nainital - 263002 INDIA. \\ Corresponding address: vyomeshpant@yahoo.co.in \\ Received 14 September, 2010; Revised 14 March, 2011
}

\begin{abstract}
The present paper is aimed at obtaining common fixed point theorems for a pair of selfmaps satisfying nonexpansive or Lipschitz type condition by using the notion of pointwise R- weak commutativity but without assuming the completeness of the space or continuity of the mappings involved.
\end{abstract}

Key Words and Phrases: Lipschitz type mapping pairs, nonexpansive conditions, noncompatible mappings, Pointwise R-weak commutativity, contractive conditions.

Mathematics Subject Classification: 54 H 25.

\section{INTRODUCTION}

The study of common fixed points of compatible mappings emerged as an area of intense research activity ever since Jungck [1] introduced the notion of compatible mappings in 1986. However, the study of common fixed points of noncompatible mappings is also interesting. Work on these lines has recently been initiated by Pant $[3,4,5,6]$. In the study of common fixed points of compatible mappings we often require assumptions on completeness of the space or continuity of the mappings involved besides some contractive condition, but the study of fixed points of noncompatible mappings can be extended to the class of nonexpansive or Lipschitz type mappings pairs [5] even without assuming continuity of the mappings involved or completeness of the space.

Two selfmaps $\mathrm{f}, \mathrm{g}$ of a metric space $(\mathrm{X}, \mathrm{d})$ are called R-weakly commuting (see Pant [2] ) if there exists some real number $R>0$ such that $d(f g x, g f x) \leq R(d(f x, g x)$ ) for all $x$ in $X$. $f$ and $g$ are called pointwise $R$-weakly commuting if given $x$ in $X$, there exists $R>0$ such that $\mathrm{d}(\mathrm{fgx}, \mathrm{gf} \mathrm{x}) \leq \mathrm{R}(\mathrm{d}(\mathrm{f} \mathrm{x}, \mathrm{gx}))$.

It was proved by the first author $[3,4,7]$ that pointwise $\mathrm{R}$-weak commutativity is

(i) equivalent to commutativity at coincident points; and

(ii) a necessary, hence minimal, condition for the existence of common fixed points of contractive type mappings.

Two selfmaps $\mathrm{f}$ and $\mathrm{g}$ of a metric space $(\mathrm{X}, \mathrm{d})$ are called compatible (see Jungck [1]) if $\lim _{n} d\left(f g x_{n}, g f x_{n}\right)=0$, whenever $\left\{x_{n}\right\}$ is a sequence in $X$ such that $\lim _{n} f x_{n}=\lim _{n} g x_{n}=t$ for some $t$ in $\mathrm{X}$. It is clear from the above definition that $\mathrm{f}$ and $\mathrm{g}$ will be noncompatible if there exists at least one sequence $\left\{x_{n}\right\}$ such that $\lim _{n} f_{n}=\lim _{n} g x_{n}=t$ for some $t$ in $X$ but 
$\lim _{n} d\left(f g x_{n}, g f x_{n}\right)$ is either non-zero or non-existent. Compatibility implies pointwise R-weak commutativity since compatible maps commute at their coincidence points. However, as shown in the examples on the following pages, pointwise R-weakly commuting maps need not be compatible.

In the present paper, we obtain common fixed point theorems for a pair of mappings satisfying nonexpansive or Lipschitz type condition by employing the notion of pointwise Rweak commutativity and simple techniques of contraction maps.RESULTS

THEOREM 1: Let $\mathrm{f}$ and $\mathrm{g}$ be noncompatible pointwise R-weakly commuting selfmappings

of a metric space $(X, d)$ satisfying

(i) $\overline{f X} \subset \mathrm{gX}$, where $\overline{f X}$ denotes the closure of range of $\mathrm{f}$.

(ii) $\mathrm{d}(\mathrm{fx}, \mathrm{fy}) \leq \mathrm{kd}(\mathrm{gx}, \mathrm{gy}), \mathrm{k} \geq 0$, and

(iii) $\mathrm{d}\left(\mathrm{fx}, \mathrm{f}^{2} \mathrm{x}\right)<\max \left\{\mathrm{d}(\mathrm{gx}, \mathrm{gfx}), \mathrm{d}(\mathrm{fx}, \mathrm{gx}), \mathrm{d}\left(\mathrm{f}^{2} \mathrm{x}, \mathrm{gfx}\right), \mathrm{d}(\mathrm{fx}, \mathrm{gfx}), \mathrm{d}\left(\mathrm{gx}, \mathrm{f}^{2} \mathrm{x}\right)\right\}$ whenever $f x \neq f^{2} x$

Then $\mathrm{f}$ and $\mathrm{g}$ have a common fixed point.

PROOF: Since $f$ and $g$ are noncompatible, there exists a sequence $\left\{x_{n}\right\}$ such that $f x_{n} \rightarrow t$ and $\mathrm{gx}_{\mathrm{n}} \rightarrow \mathrm{t}$ for some $\mathrm{t}$ in $\mathrm{X}$ but $\lim _{\mathrm{n}} \mathrm{d}\left(\mathrm{fgx}_{\mathrm{n}}, \mathrm{gfx_{ \textrm {n } }}\right)$ is either nonzero or nonexistent. Then, since $t \in \overline{f X}$ and $\overline{f X} \subset \mathrm{gX}$ there exists $\mathrm{u}$ in $\mathrm{X}$ such that $\mathrm{t}=\mathrm{gu}$. By (ii) we now get

$$
\mathrm{d}(\mathrm{fx}, \mathrm{fu}) \leq \mathrm{kd}\left(\mathrm{gx}_{\mathrm{n}}, \mathrm{gu}\right)
$$

On letting $\mathrm{t} \rightarrow \infty$ we get $\mathrm{fu}=\mathrm{gu}$. Pointwise R-weak commutativity of $\mathrm{f}$ and $\mathrm{g}$ implies that $\mathrm{fgu}=\mathrm{gfu}$. Also, $\mathrm{ffu}=\mathrm{fgu}=\mathrm{gfu}=\mathrm{ggu}$. We claim that $\mathrm{ffu}=\mathrm{fu}$. If not, by virtue of (iii) we get

$$
\begin{aligned}
\mathrm{d}(f u, f f u) & <\max \{d(g u, g f u), d(f u, g u), d(f f u, g f u), d(f u, g f u), d(g u, f f u)\} \\
& =d(f u, f f u)
\end{aligned}
$$

a contradiction. Hence $\mathrm{fu}=\mathrm{ffu}=\mathrm{gfu}$ and $\mathrm{fu}$ is a common fixed point of $\mathrm{f}$ and $\mathrm{g}$. This completes the proof of the theorem.

We now give an example to illustrate the above theorem.

EXAMPLE 1: Let $X=[2,20]$ and $d$ be the usual metric on $X$. Define $f, g: X \rightarrow X$ as

$$
\begin{aligned}
& \mathrm{fx}=2 \quad \text { if } \quad \mathrm{x}=2 \text { or }>5, \quad \mathrm{fx}=6 \quad \text { if } 2<\mathrm{x} \leq 5 \\
& \mathrm{~g} 2=2, \mathrm{gx}=7 \quad \text { if } 2<\mathrm{x} \leq 5, \quad \mathrm{gx}=(4 \mathrm{x}+10) / 15 \quad \text { if } \mathrm{x}>5
\end{aligned}
$$


Then $f$ and $g$ satisfy all the conditions of the above theorem and have a unique common fixed point at $\mathrm{x}=2$.

In this example $f X=\{2\} U\{6\}$ and $g X=[2,6] U\{7\}$. It may be seen that $\overline{f X}$ $\subset \mathrm{gX}$. It can be verified also that $\mathrm{f}$ and $\mathrm{g}$ are pointwise $\mathrm{R}$-weakly commuting maps. $\mathrm{f}$ and $\mathrm{g}$ are pointwise R-weakly commuting since they commute at their coincidence points. To see that $f$ and $g$ are noncompatible, let us consider a sequence $\left\{x_{n}=5+1 / n: n>1\right\}$, then $\lim _{n} f_{n}=2, \lim _{n} g x_{n} \rightarrow 2, \lim _{n} f g x_{n}=6$ and $\lim _{n} g f x_{n}=2$. Hence $f$ and $g$ are noncompatible. It can be verified that $\mathrm{f}$ and $\mathrm{g}$ satisfy the Lipschitz type condition

$$
\mathrm{d}(\mathrm{fx}, \mathrm{fy}) \leq \mathrm{kd}(\mathrm{gx}, \mathrm{gy}) \text { with } \mathrm{k}=4
$$

together with the condition

$$
d\left(f x, f^{2} x\right)<\max \left\{d(g x, g f x), d(f x, g x), d\left(f^{2} x, g f x\right), d(f x, g f x), d\left(g x, f^{2} x\right) .\right.
$$

As a corollary of above result we now give the following theorem.

THEOREM 2: Let $\mathrm{f}$ and $\mathrm{g}$ be noncompatible pointwise R-weakly commuting selfmappings of a metric space $(X, d)$ satisfying condition (i) and (ii) of theorem 1 and

$$
\text { (iii) } \mathrm{d}\left(\mathrm{fx}, \mathrm{f}^{2} \mathrm{x}\right)>\max \left\{\mathrm{d}(\mathrm{gx}, \mathrm{gfx}), \mathrm{d}(\mathrm{fx}, \mathrm{gx}), \mathrm{d}\left(\mathrm{f}^{2} \mathrm{x}, \mathrm{gfx}\right), \mathrm{d}(\mathrm{fx}, \mathrm{gfx}), \mathrm{d}\left(\mathrm{gx}, \mathrm{f}^{2} \mathrm{x}\right)\right\}
$$

whenever $f x \neq f^{2} x$

Then $\mathrm{f}$ and $\mathrm{g}$ have a common fixed point.

The theorem can be proved in similar manner as in theorem 1. To illustrate the theorem we give an example.

EXAMPLE 2: Let $X=[2,20]$ and $d$ be the usual metric on $X$. Define $f, g: X \rightarrow X$ as

$$
\begin{aligned}
& \mathrm{fx}=2 \quad \text { if } \quad \mathrm{x}=2 \text { or }>5, \quad \mathrm{fx}=8 \quad \text { if } 2<\mathrm{x} \leq 5 \\
& \mathrm{~g} 2=2, \quad \mathrm{gx}=7 \quad \text { if } 2<\mathrm{x} \leq 5, \quad \mathrm{gx}=(4 \mathrm{x}+10) / 15 \quad \text { if } \mathrm{x}>5
\end{aligned}
$$

Then $\mathrm{f}$ and g satisfy all the conditions of the above theorem and have a unique common fixed point at $\mathrm{x}=2$.

It may be seen that in the example above $\mathrm{f}$ and $\mathrm{g}$ satisfy all the conditions of Theorem 2 with $\mathrm{k}=6$.

As a corollary of Theorem 1 ibid, we get a common fixed point theorem for nonexpansive type mapping pairs. We formally state it as follows.

Corollary 1: Let $\mathrm{f}$ and $\mathrm{g}$ be noncompatible pointwise R-weakly commuting selfmappings of a

metric space $(X, d)$ satisfying 
(i) $\overline{f X} \subset \mathrm{gX}$, where $\overline{f X}$ denotes the closure of range of $\mathrm{f}$.

(ii) $\mathrm{d}(\mathrm{fx}, \mathrm{fy}) \leq \mathrm{d}(\mathrm{gx}, \mathrm{gy})$, and

(iii) $\mathrm{d}\left(\mathrm{fx}, \mathrm{f}^{2} \mathrm{x}\right)<\max \left\{\mathrm{d}(\mathrm{gx}, \mathrm{gfx}), \mathrm{d}(\mathrm{fx}, \mathrm{gx}), \mathrm{d}\left(\mathrm{f}^{2} \mathrm{x}, \mathrm{gfx}\right), \mathrm{d}(\mathrm{fx}, \mathrm{gfx})\right.$, $\left.\mathrm{d}\left(\mathrm{gx}, \mathrm{f}^{2} \mathrm{x}\right)\right\}$ whenever $\mathrm{fx} \neq \mathrm{f}^{2} \mathrm{x}$

Then $\mathrm{f}$ and $\mathrm{g}$ have a common fixed point.

Above result be proved in the similar lines of theorem 1. To illustrate our argument we now give an example.

EXAMPLE 3 : Let $X=[2,20]$ and $d$ be the usual metric on $X$. Define $f, g: X \rightarrow X$ as

$$
\begin{array}{lll}
\mathrm{fx}=2 & \text { if } \quad \mathrm{x}=2 \text { or }>5, & \mathrm{fx}=6 \quad \text { if } 2<\mathrm{x} \leq 5 \\
\mathrm{~g} 2=2, & \mathrm{gx}=10 \text { if } 2<\mathrm{x} \leq 5, & \mathrm{gx}=(4 \mathrm{x}+10) / 15 \quad \text { if } \mathrm{x}>5
\end{array}
$$

Then $f$ and g satisfy all the conditions of the corollary 1 and have a unique common fixed point at $\mathrm{x}=2$.

In this example $\mathrm{fX}=\{2\} \mathrm{U}\{6\}$ and $\mathrm{gX}=[2,6] \mathrm{U}\{10\}$. It may be seen that $\overline{\mathrm{f} X}$ $\subset \mathrm{gX}$. It can be verified also that $\mathrm{f}$ and $\mathrm{g}$ are pointwise R-weakly commuting maps. $\mathrm{f}$ and $\mathrm{g}$ are pointwise R-weakly commuting since they commute at their coincidence points. To see that $\mathrm{f}$ and $\mathrm{g}$ are noncompatible, let us consider a sequence $\quad\left\{\mathrm{x}_{\mathrm{n}}=5+1 / \mathrm{n}: \mathrm{n}>\right.$ $1\}$, then $\lim _{n} f_{x_{n}}=2, \lim _{n} g x_{n} \rightarrow 2, \lim _{n} f g x_{n}=6$ and $\lim _{n} g f x_{n}=2$. Hence $f$ and $g$ are noncompatible. It can be verified that $f$ and $g$ satisfy the condition $\quad d(f x, f y) \leq d(g x, g y)$ together with the condition $d\left(f x, f^{2} x\right)<\max \left\{d(g x, g f x), d(f x, g x), d\left(f^{2} x, g f x\right), d(f x, g f x)\right.$, $\mathrm{d}\left(\mathrm{gx}, \mathrm{f}^{2} \mathrm{x}\right)$.

\section{ACKNOWLEDGEMENT}

The author is very much thankful to the referee for providing valuable comments to improve the paper.

\section{REFERENCES}

[1] Jungck G, Compatible mappings and common fixed points, Internat. J. Math. Math. Sci. 9 (1986), 771.

[2] Pant R P, Common fixed points of noncommuting mappings, J. Math. Anal. Appl. 188 (1994), 436.

[3] Pant R P, R-weak commutativity and common fixed points of noncompatible maps, Ganita, 49 (1998), 19. 
[4] Pant R P, Common fixed point theorems for contractive maps, J. Math. Anal. Appl., 226 (1998), 251.

[5] Pant R P, Common fixed points of Lipschitz type mapping pairs, J. Math. Anal. Appl., 240 (1999), 280.

[6] Pant R P, Discontinuity and fixed points, J. Math. Anal. Appl., 240 (1999), 284.

[7] Pant R P, R-weak Commutativity and common fixed points, Soochow J. Math., 25 (1999), 37. 